\title{
Consideraciones éticas en épocas de epidemias y pandemias. Una mirada de asombro en tiempos de COVID-19
}

\section{Ethical considerations in times of epidemics and pandemics. A look of amazement in the days of COVID-19}

\author{
Ma. Eugenia Garay-SeVilia*, Ma. Luisa Ávalos-Montoya, Verónica I. Tovar-Villegas, Edgar S. Daza-Hernández, \\ Dax H. Galván-Martínez, Vanessa Coria-Caballero, Samantha Hernández-Torres, Laura Ma. Navarro-Flores, \\ IRAIS G. ORTEGA-BARRÓN y ABRIL A. REYES-DOMÍNGUEZ
}

Departamento de Ciencias Médicas, División Ciencias de la Salud, Universidad de Guanajuato, Campus León, León, Guanajuato, México

\section{RESUMEN}

El 11 de marzo del 2020, la Organización Mundial de la Salud declaró que el brote del coronavirus 2 del síndrome respiratorio agudo grave (SARS-CoV-2), causante de la enfermedad por coronavirus 2019 (COVID-19), es una pandemia. La gravedad de esta enfermedad ha puesto en alerta a todo el mundo y plantea dilemas éticos y morales. Sin embargo, es importante resaltar que incluso en épocas de crisis los principios éticos centrales como el respeto a la autonomía, la beneficencia, la no maleficencia y la justicia siguen siendo los mismos (incluso si algunos se vuelven más significativos que otros a medida que surgen nuevos contextos), ya que la ética está supeditada a la realidad social en la que se encuentran las personas y los sucesos imprevisibles que se pueden suscitar en esta, como en este caso la COVID-19. Estos aspectos éticos los abordaremos en la presente revisión; además recordaremos un poco de la historia de la humanidad en épocas de epidemias y pandemias y los retos éticos a los que se enfrentaron. Una pandemia como la que nos está tocando vivir puede ser un área de oportunidad para reflexionar y progresar hacia una salud más justa y equitativa, con una sociedad y personas más comprometidas con su salud y respetuosas del bien común.

Palabras clave: COVID-19. Pandemia. Dilemas éticos.
ABSTRACT

On March 11, 2020, the World Health Organization declared that the outbreak of the severe acute respiratory syndrome coronavirus 2 (SARS-CoV-2), that causes the coronavirus disease 2019 (COVID-19), is a pandemic. The severity of this disease has alerted everyone and poses ethical and moral dilemmas. However, it is important to highlight that even in times of crisis, central ethical principles such as respect for autonomy, beneficence, non-maleficence and justice remain the same (even if some become more significant than others as new contexts emerge), since ethics is subject to the social reality in which people find themselves and the unforeseeable events that may arise in it, as in this case, COVID-19. We will address these ethical aspects in this review; we will also recall a little bit of the history of humanity in times of epidemics and pandemics and the ethical challenges they faced. A pandemic likes the one we are living in can be an area of opportunity to reflect and progress towards fairer and more equitable health, in addition to a society and people more committed to their health and respectful of the common good.

Key words: COVID-19. Pandemic. Ethical dilemmas.
Correspondencia:

*Ma. Eugenia Garay-Sevilla

E-mail: marugaray_2000@yahoo.com
Fecha de recepción: 15-05-2020

Fecha de aceptación: 16-06-2020

DOI: 10.24875/RME.20000053
Disponible en internet: 03-07-2020

Rev Mex Endocrinol Metab Nutr. 2021;8:3-12

2462-4144 / @ 2020 Sociedad Mexicana de Nutricion y Endocrinologia, AC. Publicado por Permanyer. Éste es un artículo open access bajo la licencia CC BY-NC-ND (http://creativecommons.org/licenses/by-nc-nd/4.0/). 


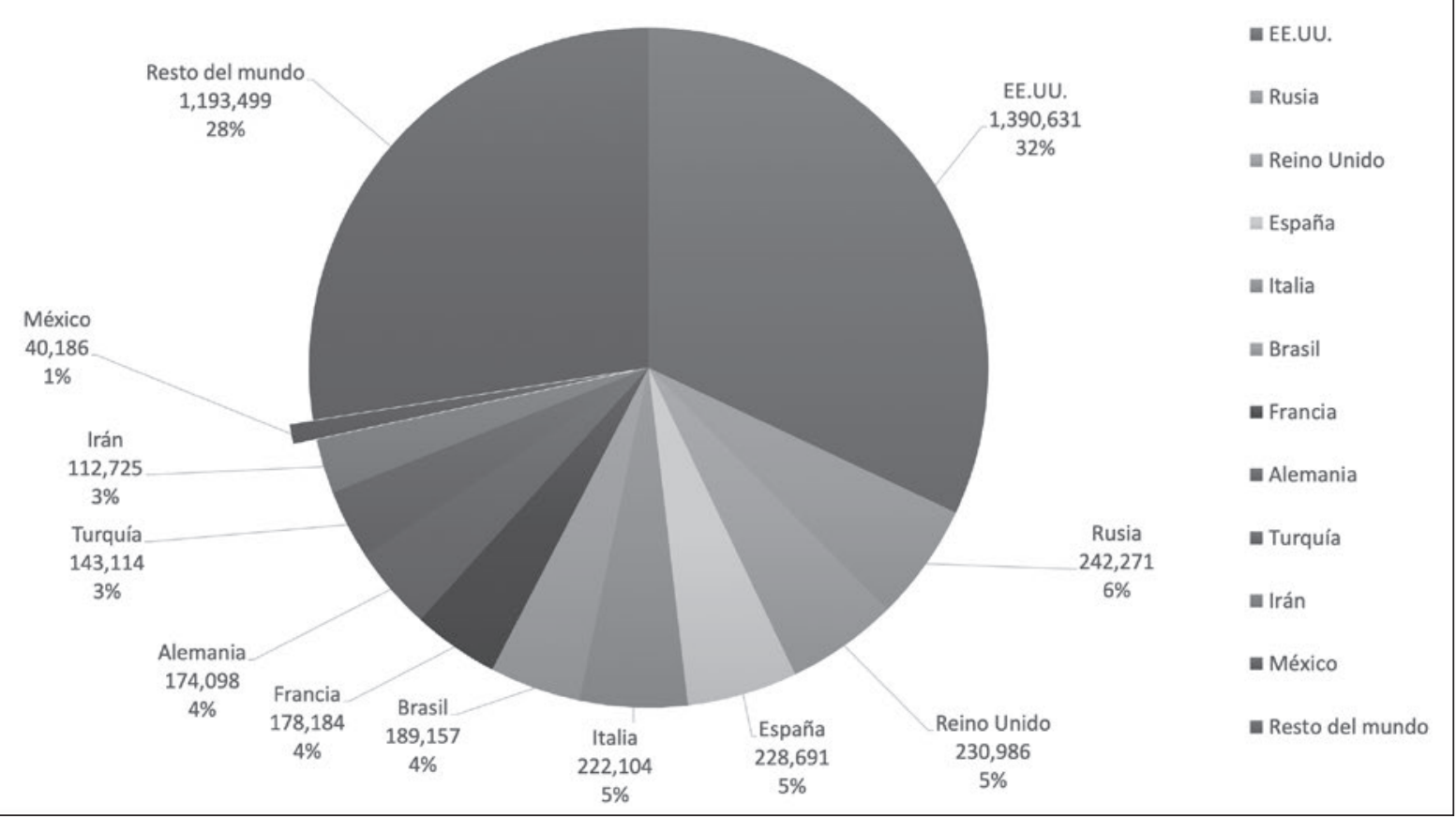

Figura 1. COVID-19: los 10 países con más casos confirmados, México y el resto del mundo (adaptada de Johns Hopkins University, 2020³).

\section{ENFERMEDAD POR EL SARS-COV-2}

La enfermedad por coronavirus 2019 (COVID-19), que causa afecciones respiratorias graves como neumonía e insuficiencia pulmonar, se informó por primera vez en Wuhan, la capital de Hubei (China) en 2019. El agente etiológico de la COVID-19 ha sido confirmado como un nuevo coronavirus, el coronavirus 2 del síndrome respiratorio agudo severo (SARS-CoV-2) ${ }^{1}$. El 11 de marzo del 2020, la Organización Mundial de la Salud (OMS) declaró que el brote del SARS-CoV-2 (COVID-19) es una pandemia. En ese momento había más de 118,000 casos en 114 países, y 4,291 personas habían perdido la vida. Para el 25 de marzo había más de 400,000 casos confirmados y cerca de 18,000 muertes $^{2}$ y para el 11 de mayo se registraron más de 4 millones de infectados y casi 88 mil muertes a nivel mundial, con casi 2 millones de casos confirmados en el continente americano ${ }^{3}$ (Fig. 1). En México, el 30 de marzo de 2020, mediante el acuerdo publicado en el Diario Oficial de la Federación, el Consejo de Salubridad General reconoce la epidemia de la COVID-19 como una enfermedad grave de atención prioritaria y se establecen las actividades de preparación y respuesta ante dicha pandemia ${ }^{4}$.
EI SARS-CoV-2 se considera un nuevo $\beta$-coronavirus que infecta a humanos y animales salvajes. La trasmisión ocurre persona-persona vía contacto directo o por medio de microgotas propagadas al toser o estornudar; no obstante, puede ser trasmitido por personas asintomáticas, eso explica la expansión espontánea del virus por el mundo. Los síntomas más comunes son fiebre, tos, fatiga y otros menos comunes como disnea, dolor de cabeza, diarrea, entre otros. El diagnóstico clínico se obtiene mediante una radiografía de tórax y la sintomatología ${ }^{1}$. Actualmente no hay un antiviral específico o vacuna para prevenir la COVID 19, por lo que las medidas de prevención de contagio son de la mayor importancia e incluyen el lavado de manos recurrente, el distanciamiento social y mantener limpios los objetos y superficies, ya que son importantes vías de transmisión ${ }^{1}$ (Fig. 2).

Estamos viviendo tiempos verdaderamente novedosos y la gravedad de la pandemia de COVID-19 plantea dilemas éticos y morales, que abordaremos a continuación; sin embargo, es importante recordar un poco de la historia de la humanidad en épocas de epidemias y pandemias, así como la ética y sus principios. 


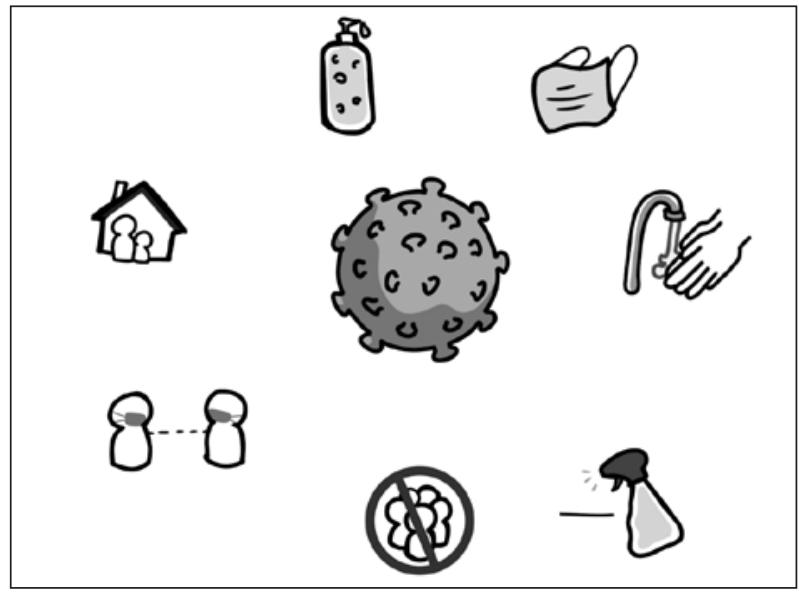

Figura 2. Medidas de prevención de contagio.

\section{UNA MIRADA A LA HISTORIA DE LAS PRINCIPALES PANDEMIAS EN EL MUNDO Y LOS ASPECTOS ÉTICOS}

Se ha documentado que durante la Edad Media, la medicina no era la ciencia que conocemos en la actualidad, sino una labor ejercida por un sinfín de practicantes que iban desde herbolarios que se jactaban de ser hechiceros, hasta médicos y cirujanos egresados de alguna universidad, por lo que el conocimiento sobre las enfermedades y sus tratamientos eran muy diversos y no se guiaban por un método para la práctica clínica. Aunado a lo anterior, la calidad de vida durante este periodo era bastante precaria y las malas condiciones sanitarias favorecían la aparición y propagación de pestes y epidemias ${ }^{5}$.

\section{La viruela}

La viruela fue una de las enfermedades más infecciosas y contagiosas a nivel mundial en la historia de la humanidad. Se cree que apareció alrededor del año 10,000 a.C. en el noreste de África y se difundió hacia la India. Posteriormente, su llegada a Europa fue alrededor del siglo $\mathrm{V}$, causando diversas epidemias durante la Edad Media. Con el descubrimiento del continente americano por los europeos, se diseminó hacia el nuevo mundo, lo cual se consideró un factor determinante para la derrota del Imperio azteca en la colonización española 6 . Se piensa que fue introducida a México desde Cuba en 1790 y, posteriormente, desde Perú y Guatemala en el periodo de 1796 a 17987.

Dentro de las medidas de prevención usadas para evitar el contagio durante el Virreinato en la Nueva España, se encontraban: la cuarentena de las principales ciudades; la creación de las Juntas de Caridad, que fungían como proveedores de alimentos, medicinas y ropa a los enfermos; y la posterior variolización en algunas poblaciones por decreto real, con el fin de combatir la epidemia en el nuevo continente ${ }^{7}$.

\section{La peste negra}

La peste negra se presentó alrededor de 1347 y 1351, fue la pandemia más grande y devastadora del siglo XIV, que provocó la muerte de aproximadamente un tercio de la población europea ${ }^{8}$. En esta época se evidenció el gran vacío ético sobre las responsabilidades de los médicos durante la pandemia por diversos motivos. Primeramente, los médicos no estaban obligados por algún principio de ética a cumplir con su trabajo o atender a la población sin importar la clase social, la mayoría de ellos trabajan por honorarios, por lo que la clase baja fue la que más sufrió los estragos de la pandemia. Además, la iglesia cristiana gozaba de un gran poder sobre la población en general y, probablemente, influyó en la toma de decisiones médicas prefiriendo siempre anteponer las convicciones religiosas sobre la práctica médica. Sin embargo, se debe reconocer que los médicos medievales tuvieron que afrontar solos la peste negra, recurriendo tanto a sus creencias religiosas como a su sentido de obligación profesional ${ }^{5}$.

Fue creencia popular que la peste negra era un castigo divino e incluso algunos médicos creyeron que podían curarla con brebajes y otros con oraciones religiosas, aunque ninguno de ellos tuvo éxito. Al aumentar el número de casos de infectados y de muertes, se establecieron medidas como el aislamiento de los pacientes contagiados para evitar la propagación. Por otro lado, algunos médicos decidieron huir de las áreas más afectadas, otros fallecieron por el cansancio o por la infección, y otros se quedaron y comenzaron a cobrar por el asesoramiento médico e incluso por consejos espirituales, demostrando que en la Edad Media la práctica médica distaba mucho de ser organizada y sistematizada ${ }^{5,8}$. 


\section{La gripe española}

Entre los años 1918 y 1919 surge en la población mundial la pandemia considerada la más devastadora de la historia, la gripe española (causada por el virus de la influenza $A$ H1N1). Si bien algunos autores refieren que no inició en España, tras registrarse los primeros casos en Europa la gripe pasó a España, un país neutral en la Primera Guerra Mundial que no censuró la publicación de los informes sobre la enfermedad y sus consecuencias, por esta razón se la conoció como la gripe española. A pesar de no ser el epicentro, España fue uno de los países más afectados, con 8 millones de personas infectadas y 300.000 personas fallecidas. Debido a la Primera Guerra Mundial, las medidas sanitarias y la calidad de vida no eran las óptimas, lo que provocó la rápida propagación de la enfermedad entre la población y a nivel global provocó la muerte de más de 40 millones de personas en menos de un año. La gravedad de esta pandemia evidenció la escasa efectividad de los recursos médicos de la época, pese a que algunas especialidades médicas, como la bacteriología, se encontraban en pleno apogeo ${ }^{10-12}$. Por aquella época se haría popular la máscara de tela y gasa con la que la población se sentía más tranquila, aunque no era muy útil ${ }^{13}$.

La gravedad del problema y el gran número de infectados llevó a la escasez de médicos y los que hicieron frente a la pandemia, enfermaron, y muchos de ellos murieron, por lo que estudiantes de medicina tuvieron que ocupar puestos dentro del personal médico y se habilitaron espacios públicos para hacer hospitales improvisados. En su esfuerzo por prevenir la propagación de la enfermedad, diversas ciudades aplicaron diferentes medidas como la promoción de una buena higiene personal, el cierre de lugares públicos como escuelas y teatros, la prohibición de aglomeraciones, el aislamiento o cuarentena y en algunas ciudades el uso de mascarillas en público era considerado obligatorio ${ }^{12}$. Lo anterior logró que se controlaran en mayor medida las muertes debidas a la pandemia.

Algunos autores refieren que «la experiencia de 1918 sugiere que políticas de contención sostenidas en el tiempo son beneficiosas y deben mantenerse después de que el pico de letalidad haya pasado» ${ }^{14}$. Son varios los brotes de gripe española que se han presentado a lo largo de la historia, por lo que la OMS, en el 2007, elaboró un documento donde aborda problemas relacionados con la salud públi$\mathrm{ca}$, principalmente aquellos que pueden surgir durante una posible pandemia por influenza ${ }^{15}$, que abordaremos más ampliamente líneas abajo.

\section{El sarampión}

El sarampión es una enfermedad de origen viral sumamente contagiosa. Antes de que se desarrollara una vacuna, existía una gran cantidad de casos. Por ejemplo, en Chile se reportaron hasta 10,000 casos anuales en años anteriores a 1958, año en el cual comenzaron a duplicarse. Afortunadamente, en 1964, con la integración de la vacuna en el calendario de vacunación, los casos comenzaron a disminuir $^{16}$. Sin embargo, esta enfermedad no ha sido completamente erradicada, como es el caso del reciente brote en el Estado de México, donde se presentan $163 \operatorname{casos}^{17}$ y se ha documentado que hay un número importante de pacientes que no cuentan con la vacunación, lo que podría representar un potencial problema de salud pública.

\section{El virus de la inmunodeficiencia humana}

Otra gran pandemia dentro de la historia humana es la suscitada por el virus de la inmunodeficiencia humana (VIH), que ocasiona el síndrome de inmunodeficiencia adquirida (SIDA). Su origen ha sido objeto de mucho debate e investigación desde que fuera identificado en la década de los 80; en 1981 fueron diagnosticados en E.U.A. los primeros pacientes que vivían con SIDA. EI VIH se trasmite por medio del intercambio directo de líquidos corporales, como la sangre, la leche materna, el semen o las secreciones vaginales, además se puede transmitir de la madre al hijo durante el embarazo y el parto ${ }^{18}$. El riesgo de infección se reduce limitando la exposición a los factores de riesgo, como por ejemplo con el uso de preservativos y evitando la reutilización de jeringas y agujas, además del tratamiento antiviral en mujeres embarazadas contagiadas ${ }^{19}$.

De acuerdo con cifras de la Organización de las Naciones Unidas (ONU), se estima que existen 37.7 
millones de personas que viven con VIH/SIDA, de los cuales únicamente 23 millones de personas (62\%) tienen acceso a terapia antirretroviral. En el 2018, 1.7 millones contrajeron el virus ${ }^{20}$.

Los problemas éticos son uno de los componentes más importantes de la pandemia de VIH/SIDA. En este caso se establece una dinámica, interrelación entre el médico, el paciente y la sociedad, aplicándose los principios de bioética, donde el médico se rige por el principio de la beneficencia, el enfermo por el principio de autonomía y la sociedad por el principio de justicia. Durante el tratamiento de personas que viven con $\mathrm{VIH}$, el médico se enfrenta a problemas y dilemas éticos de trascendental importancia. El SIDA conlleva un riesgo real de discriminación al que están expuestas las personas que viven con $\mathrm{VIH}$. Por este motivo resulta indispensable el respeto a los principios de la confidencialidad y privacidad, porque si se violan se exponen a los pacientes a serios riesgos de discriminación por el estigma que se continúa teniendo en la actualidad sobre los portadores que viven con $\mathrm{VIH}^{21}$.

\section{El virus de la influenza porcina tipo A H1N1}

La historia de la primera pandemia del siglo XXI inició oficialmente el 21 de abril de 2009, con dos casos de infección respiratoria aguda en EE.UU. ocasionada por un virus de influenza $A$ negativo a los subtipos conocidos; posteriormente, el 11 de junio del mismo año, la OMS declaró el inicio de la pandemia por influenza ${ }^{20}$, que causó alrededor de 284,500 muertes en el mundo hasta el 10 de agosto del 2010, cuando la OMS declaró el fin de la pandemia ${ }^{22}$.

La influenza A H1N1, en humanos, es causada por el virus de la influenza $A$ y su descripción es dada por dos proteínas (hemaglutininas y neuraminidasas) presentes en la membrana celular externa que facilitan la entrada y liberación viral; el virus proviene de una cepa porcina que pasó a los humanos por la vía de la ruta respiratoria. Se dirige a las células epiteliales del aparato respiratorio, ocasionando la infección y su gravedad se asocia con la replicación del virus en el tracto respiratorio inferior ${ }^{22}$.

Actualmente, la influenza A H1N1 se caracteriza por causar epidemia estacional y la falta de inmunidad prexistente en el humano se asocia con mayor gravedad y mortalidad, por lo que la vacuna anual junto a medicamentos antivirales es la única medida preventiva ${ }^{23}$.

La OMS propone algunas consideraciones éticas frente a la influenza pandémica, como incrementar el conocimiento público sobre los riesgos relacionados con la enfermedad, transparencia y pronta comunicación con la población, facilitar el acceso al tratamiento, proporcionar los recursos al personal médico, priorizar la vacunación de personas vulnerables y desarrollar capacidades básicas de vigilancia y respuesta de la salud pública como cuarentena, control de fronteras y medidas de aislamiento social ${ }^{24}$.

\section{El virus del Ébola}

La enfermedad por el virus del Ébola (EVE) es una enfermedad grave, a menudo mortal, que se detectó por vez primera en 1976 en dos brotes simultáneos ocurridos en Nzara y Yambuku. La aldea en que se produjo el segundo de ellos está situada cerca del río Ébola, que da nombre al virus ${ }^{25}$. El brote de EVE de 2014 en África Occidental fue el más extenso y complejo desde que se descubrió el virus. Este virus se transmite a partir de la manipulación o ingestión de animales infectados y entre humanos por medio del contacto directo con los fluidos corporales de otra persona infectada, como sangre, heces, saliva, moco y sudoración, entre otros ${ }^{26}$.

En vista de la emergencia sanitaria por la rápida expansión del virus a otros países como Guinea, Sierra Leonas y Liberia, la OMS convocó el 11 de agosto de 2014 a una reunión consultiva y tras analizar la falta de control del brote, se debatió la posible utilización de fármacos y vacunas que estaban en fase de investigación y se evaluaron las implicaciones éticas que tendría el posible uso de intervenciones no comprobadas. Al finalizar la pandemia, en 2016, se registró un gran número de personas afectadas por el brote, con una alta tasa de mortalidad (más de 11,000 personas) ${ }^{26}$.

La OMS acordó por consenso que en las circunstancias particulares de este brote, y siempre que se cumplan determinadas condiciones, es ético ofrecer 
intervenciones no probadas, con fines potencialmente terapéuticos o preventivos ${ }^{27}$; el uso de esas intervenciones debe regirse por principios como la transparencia de todos los aspectos de la atención, el consentimiento informado, la libertad de elección, la confidencialidad, el respeto a las personas, la protección de su dignidad y la participación de la comunidad, además de dar a conocer todos los datos generados, incluidos los derivados de los tratamientos administrados de forma compasiva ${ }^{26}$.

\section{LA ÉTICA Y SUS PRINCIPIOS}

En sus orígenes, la ética trataba sobre el pensamiento de la vida excelente o virtuosa, donde «bueno» (agthós) era (y sigue siendo) el concepto ético por antonomasia. Sin embargo, este concepto ha evolucionado con el pasar del tiempo, así como lo que se considera «bueno o justo», dependiendo del tiempo histórico, social y cultural en que se encuentre ${ }^{28}$.

La ética no se limita a observar y describir las acciones, sino que busca determinar si son buenas o malas, emitir juicio sobre ellas y así ayudar a encauzar la conducta humana ${ }^{29}$. Dentro de la práctica de la medicina, en lo que respecta a la existencia de «códigos de ética médica», existe una lista tan larga como heterogénea. Empezando por el código del Rey Hammurabi, que data del año 1700 a.C., hasta 1803, cuando apareció el primer libro con el título Medical Ethics, del médico inglés Thomas Percival, y a partir de entonces y hasta el día de hoy, se han promulgado docenas de documentos que pretenden enunciar los principios de ética médica, tanto a nivel regional como nacional e internacional ${ }^{30}$.

Como se mencionó, existen en el contexto ético internacional declaraciones, pautas, guías o recomendaciones en materia de ética. Mencionaremos algunas: El Código de Núremberg, 20 de agosto de 1947; el Juramento de Hipócrates, 1948; la Declaración Universal de Derechos Humanos de la ONU, 1948; la Declaración de Helsinki, de la Asociación Médica Mundial, 1964 (última enmienda en octubre del 2013); y la Declaración Universal de los Derechos Humanos de las Generaciones Futuras, UNESCO (Organización de las Naciones Unidas para la Educación, la Ciencia y la Cultura), 199431. Hay también códigos que especifican los deberes de los médicos en general, los deberes del médico con los enfermos, los deberes de los médicos entre sí y hasta una carta de los derechos de los pacientes ${ }^{30}$. En México contamos con la Ley General de Salud y la Secretaría de Salud, por medio de la Comisión Nacional de Bioética, consolida los mecanismos institucionales que garantizan el bienestar y el respeto a los derechos de los sujetos que participan en investigaciones en salud y en el contexto de la COVID-19 ha hecho un pronunciamiento sobre la bioética ante la pandemia y se han publicado recomendaciones bioéticas, entre otros ${ }^{31}$.

Aun en épocas de crisis, los principios éticos centrales siguen siendo los mismos, incluso si algunos se vuelven más significativos que otros a medida que surgen nuevos contextos ${ }^{32}$. A continuación los mencionaremos brevemente:

- Respeto a la autonomía. Reconoce la capacidad de las personas para la toma de decisiones.

- Beneficencia y no maleficencia. Estos principios están contenidos en el imperativo ético de maximizar los posibles beneficios y minimizar los daños o riesgos potenciales.

- Justicia. Este principio implica que la distribución de cargas y beneficios sea equitativa entre las personas.

- Principio de responsabilidad. Se refiere a la necesidad que el ser humano tiene de actuar con cautela y humildad frente al enorme poder transformador de la tecnociencia.

\section{DILEMAS ÉTICOS Y MORALES EN TIEMPOS DE LA COVID-19}

Hartmann refiere que la ética está supeditada a la realidad social en la que se encuentran las personas y los sucesos imprevisibles que se pueden suscitar. La guerra, los desastres naturales y las pandemias son de este grupo de eventos que a lo largo de la historia cambian los ideales conductuales que se aspiran a seguir, siendo eventos precipitantes de cambio en los estándares éticos ${ }^{29}$. 


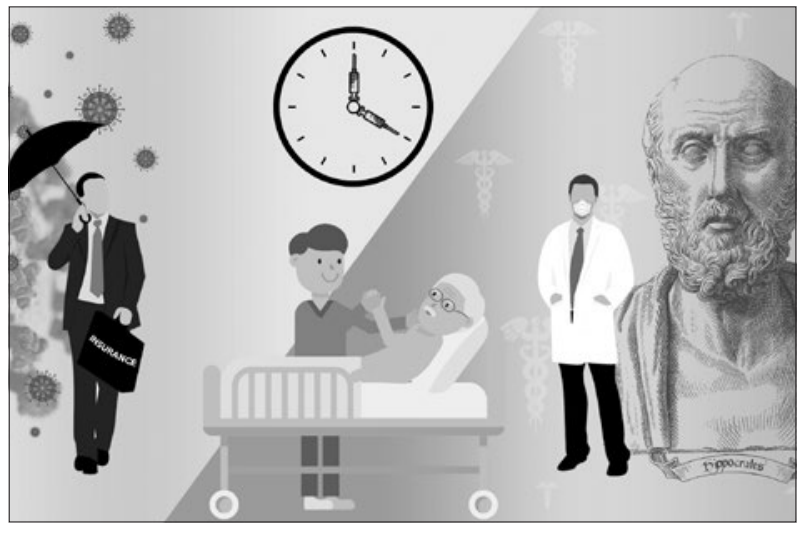

Figura 3. Dilemas éticos y morales a diferentes niveles.

En este sentido, la gravedad de la pandemia de COVID-19 ha desbordado las capacidades sanitarias de una gran cantidad de países, lo que ha desencadenado múltiples dilemas éticos y morales a diferentes niveles: la sociedad en su conjunto, los sistemas de salud, los médicos y profesionales de la salud ${ }^{33}$. Estos aspectos hace falta estudiarlos más y que sean debatidos a fondo en los sistemas de salud y en los organismos competentes en la materia (Fig. 3).

\section{La sociedad en su conjunto}

Las personas deben aceptar la posibilidad de que pueden contagiar a otros o pueden ser contagiados, por lo que representa para ellos una alta responsabilidad social el seguir al pie de la letra las indicaciones y medidas que marca la Secretaría de Salud en México y que se contemplan en «La Jornada Nacional de Sana Distancia», que consiste en: a) medidas básicas de prevención como lavado frecuente de manos, saludo a distancia y recuperación efectiva; b) suspensión temporal de actividades no esenciales, y c) protección y cuidado de las personas adultas mayores $^{34}$ (Fig. 4). Por otro lado, la Comisión Nacional de Bioética, en sus recomendaciones bioéticas ante la COVID-19, hace referencia al proceso de atención a la salud para las personas y en resumen refiere que se deben proteger los derechos humanos e integridad de las personas, valorar a la persona de manera integral, y asegurar la atención a la salud en cumplimiento a los principios de justicia, solidaridad y equidad, además de considerar el respeto a la autonomía y la dignidad de la persona ${ }^{35}$.

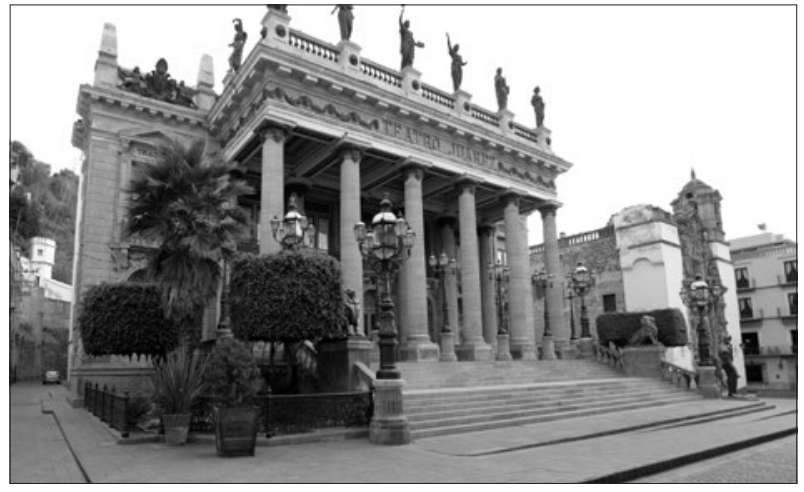

Figura 4. Durante la Jornada de Sana Distancia, calles desiertas en algunas ciudades.

\section{Los sistemas de salud}

Deben afrontar la aparición de enfermedades emergentes y adquieren una gran relevancia las medidas que es necesario que asuman las autoridades sanitarias. En este caso, ante la pandemia, maximizar el beneficio global en la distribución de los recursos para la atención; esto es, dar «la mayor cantidad de bien»; así también, el principio bioético de la justicia en la distribución de los recursos existentes y que estos sean asignados con equidad de acuerdo con las necesidades y urgencia ${ }^{33}$. En este sentido se refiere que quizás lo más difícil es cómo distribuir equitativamente los escasos recursos, como las camas de la unidad de cuidados intensivos y los ventiladores, ya que esto determinará quién vive y quién muere ${ }^{32}$. Por lo cual la OMS refiere que las autoridades de salud tienen la obligación ética de ofrecer una justificación pública de los criterios empleados para definir las prioridades de atención, así como la transparencia sobre los argumentos utilizados para las decisiones de priorización, lo cual mejorará la confianza pública, aumenta su aceptación y promueve el cumplimiento de las recomendaciones ${ }^{36}$.

\section{Los médicos y profesionales de la salud}

Son de la mayor relevancia en la atención de los pacientes con COVID-19; sin embargo, atender enfermos contagiosos constituye un riesgo que se puede atenuar, pero no suprimir con las medidas de prevención disponibles. Por lo que otro gran dilema 
ético es ¿qué tanto un trabajador de la salud debe arriesgar su vida para salvar a un paciente?, sobre todo en esta pandemia, en la cual los recursos para proteger la salud del personal médico son escasos ${ }^{37}$. Es muy importante señalar que los profesionales de la salud son también ciudadanos que tienen los mismos derechos y deberes que todos, pero la profesión médica conlleva una obligación moral estipulada en el juramento hecho al recibir el título universitario. Así también, la profesión médica se ha suscrito durante mucho tiempo a un conjunto de declaraciones éticas desarrolladas principalmente para el beneficio del paciente. Como miembro de esta profesión, un médico debe reconocer en primer lugar la responsabilidad ante los pacientes, así como ante la sociedad. Esto lo podemos documentar desde que en la primera reunión de la Asociación Médica Americana (AMA) en Filadelfia (Pensilvania), en 1847, se estableció el Código de Ética Médica, que ha tenido varias revisiones $(1903,1912,1947)$ hasta que en 1957 se realizó un cambio importante en el formato del código adoptando diez principios que fueron concebidos como expresiones de los conceptos y requisitos fundamentales del código anterior; en la última versión (2001) además se hace referencia a que los principios adoptados por la AMA no son leyes, sino estándares de conducta que definen los elementos esenciales del comportamiento honorable para el médico. Estos principios de la ética médica, como se mencionó, están centrados en el paciente. En resumen, hacen referencia a que el médico se dedicará a brindar atención médica competente, deberá mantener los estándares de profesionalismo, respetará la ley y también reconocerá la responsabilidad de buscar cambios en los requisitos que sean contrarios al mejor interés del paciente y respetará los derechos de los pacientes. Además, un médico debe considerar la responsabilidad hacia el paciente como primordial y tendrá la libertad de elegir a quién atender, con quién asociarse y el entorno en el que proporcionará atención médica, excepto en emergencias ${ }^{38}$. Sin embargo, todos estos códigos, principios y valores pueden entrar en conflicto con otros valores, deberes y responsabilidades familiares e incluso con ellos mismos.

En marzo de 2006, la OMS emprendió un proyecto conjunto sobre «abordar las cuestiones éticas en la planificación de la gripe pandémica». El documento se centra en el establecimiento de prioridades y el acceso equitativo a recursos; las restricciones en el movimiento de los individuos como consecuencia de intervenciones no farmacéuticas; las obligaciones respectivas del personal sanitario (obligaciones morales, contractuales, legales no contractuales), de sus empleadores y gobiernos. En este sentido, refiere que los gobiernos y los empleadores deberían intentar minimizar los riesgos para el personal sanitario, asegurando la existencia de sistemas adecuados de control de infecciones en los hospitales, proporcionando medidas de prevención y proporcionando al personal sanitario acceso a tratamiento psicológico, entre otros. Así también deberían asegurarse de que los trabajadores de la salud reciban educación e información adecuada sobre los riesgos asociados, las medidas que pueden adoptar para protegerse, las consecuencias legales o de otra índole que deriven de no cumplir las obligaciones laborales, etc. Así también, se hace referencia a que los gobiernos deberían realizar los máximos esfuerzos para desarrollar o potenciar sistemas de prestaciones que proporcionen prestaciones médicas y sociales en caso de enfermedad o discapacidad sanitaria durante una epidemia o pandemia, e indemnizaciones por defunciones para los familiares de trabajadores de la salud que fallezcan después de haber estado expuestos al virus de la gripe pandémica en el curso de su trabajo. En este documento, los principios éticos fundamentales sobre los que se hace hincapié son equidad, utilidad/ eficiencia, libertad, reciprocidad y solidaridad ${ }^{39}$.

Es importante señalar que en nuestro país en el pronunciamiento de la Comisión Nacional de Bioética se establece que es un requerimiento fundamental para el sistema de salud la protección de su personal con los insumos requeridos para reducir el riesgo a este sector y además en sus recomendaciones bioéticas ante la COVID-19, hace referencia a que se debe brindar apoyo a los profesionales de la salud para prevenir y atender el síndrome de desgaste profesional y el estrés moral ante la toma de decisiones en escenarios complejos, además de reconocer que se encuentran en una situación de vulnerabilidad los médicos, personal de enfermería, estudiantes de medicina y aquellos que asuman riesgos en la atención y contención de la pandemia ${ }^{35}$ (Fig. 5). 


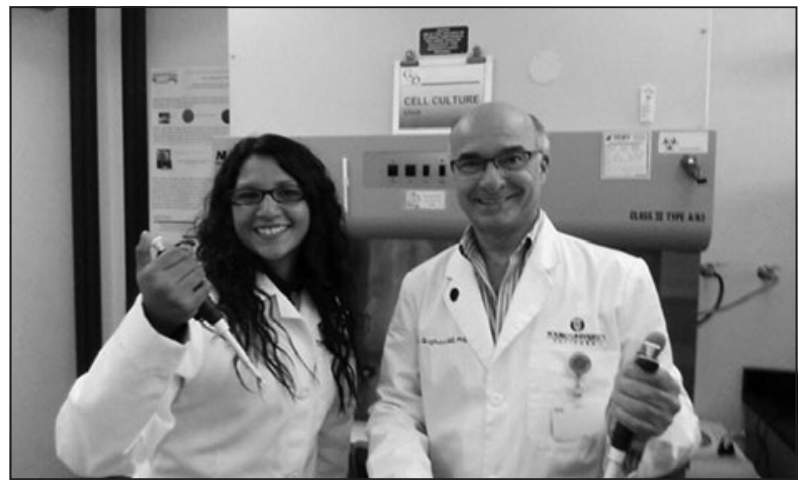

Figura 5. Profesionales de la salud.

Las respuestas a estos dilemas son múltiples y heterogéneos, y queda claro que, ante la dimensión de esta problemática, buscar el apoyo entre naciones y autoridades internacionales y científicas es la mayor fortaleza que tenemos en el mundo en que vivimos. Es por ello que organizaciones como la OMS y la Organización Panamericana de la Salud han desarrollado una guía de orientación ética sobre cuestiones planteadas por la pandemia de COVID-19. Dicha guía busca dar claridad a dudas que se pueden presentar en los gobiernos (al momento de trasmitir información a la población o implementar medidas de prevención de contagio), en los médicos y personal sanitario (sobre la práctica clínica) y en los investigadores que desarrollan estudios sobre la pandemia ${ }^{40}$.

Así también, la Secretaría de Salud de México, por medio de la Comisión Nacional de Bioética, publicó un pronunciamiento sobre la bioética ante la pandemia de COVID-19, en donde se consideran cinco ejes de análisis en el abordaje de la pandemia de COVID-19 para nuestro país ${ }^{35}$ :

1) Resulta imperativo apoyar la investigación científica, como herramienta imprescindible para desarrollar la base de conocimientos que fundamentarán las intervenciones y políticas públicas en salud.

2) Respeto por las personas y protección de grupos en condiciones de vulnerabilidad.

3) Estándares de cuidado ante contingencias y crisis epidemiológicas.

4) Innovación e investigación en salud para la producción oportuna de insumos requeridos.
5) Solidaridad y concertación de acciones con la sociedad civil.

Así también como las recomendaciones bioéticas ante la COVID-19, en donde la Comisión Nacional de Bioética hace referencia a que en el ámbito global la bioética se ha posicionado como un quehacer interdisciplinario y multidisciplinario que promueve un enfoque integral en el abordaje de la salud, y a que se han propuesto diversos modelos éticos para el abordaje de las epidemias y pandemias, dependiendo de las condiciones en que se dé el contagio, así como la naturaleza del riesgo y características del vector; no obstante, en todo caso resulta fundamental la participación de la sociedad para alcanzar los objetivos propuestos ${ }^{35}$.

\section{CONCLUSIÓN}

Esta pandemia de COVID-19 no solo ha llevado a que los servicios de salud se vean rebasados, sino que el personal de salud ha llegado en algunos casos al límite de sus capacidades físicas y emocionales. Además, en la sociedad, esta crisis ha puesto de manifiesto los valores o la falta de ellos.

Una pandemia como la que nos está tocando vivir al inicio de esta nueva década puede ser un área de oportunidad para reflexionar y progresar hacia una salud más justa y equitativa, con una sociedad y personas más comprometidos con su salud y respetuosos del bien común.

\section{FINANCIAMIENTO}

La presente investigación no ha recibido ayudas específicas provenientes de agencias del sector público, sector comercial o entidades sin ánimo de lucro.

\section{CONFLICTO DE INTERESES}

Los autores declaran no tener conflicto de intereses alguno. 
RESPONSABILIDADES ÉTICAS

Protección de personas y animales. Los autores declaran que para esta investigación no se han realizado experimentos en seres humanos ni en animales.

Confidencialidad de los datos. Los autores declaran que en este artículo no aparecen datos de pacientes.

Derecho a la privacidad y consentimiento informado. Los autores declaran que en este artículo no aparecen datos de pacientes.

\section{BIBLIOGRAFÍA}

1. Ahn D, Shin H, Kim M, Lee S, Kim H, Myoung J, et al. Current status of epidemiology, diagnosis, therapeutics, and vaccines for novel coronavirus disease 2019 (COVID-19). J Microbiol Biotechnol. 2020;30:313-24.

2. La OMS caracteriza a COVID-19 como una pandemia [Internet]. Organización Panamericana de la Salud, Organización Mundial de la Salud [fecha de consulta: 8 mayo 2020]. Disponible en: https://www.paho.org/ hq/index.php?option=com content \&view=article\&id=15756: who-characterizes-covid-19-as-a-pandemic\&ltemid=1926\&lang=es

3. COVID-19 Dashboard by the Center for Systems Science and Engineering at Johns Hopkins University [Internet]. Johns Hopkins University [fecha de consulta: 8 mayo 2020]. Disponible en: https://coronavirus.jhu.edu/map.html

4. ACUERDO por el que se reconoce la epidemia de enfermedad por el virus SARS-CoV-2 (COVID-19) en México como una enfermedad grave de atención prioritaria, así como se establecen las actividades de preparación y respuesta ante dicha epidemia [Internet]. México: Organismo [fecha de consulta: 8 mayo 2020]. Disponible en: https://www.dof.gob. $\mathrm{mx} /$ nota detalle.php? codigo $=5590161 \& \mathrm{fecha}=23 / 03 / 2020$

5. Mellinger, J. Fourteenth-century England, medical ethics, and the plague. Virtual Mentor. 2006;8(4):256-60.

6. Islas Núñez S. La viruela: El origen de una vacuna. BIOZ. 2019:(4)2.

7. Molina del Villar, A. Contra una pandemia del Nuevo Mundo: las viruelas de las décadas de 1790 en México y las campañas de vacunación de Balmis y Salvany de 1803-1804 en los dominios coloniales. III Congreso de la Asociación Latinoamericana de Población, ALAP. Córdoba, Argentina; 2008.

8. Austin W. Ethics in a time of contagion: a relational perspective. Can J Nurs Res. 2008;40(4):10-24.

9. Ahronheim J, Moreno J, Zuckerman C. Ethics in clinical practice. Sudbury, Massachusetts, EE.UU.: Jones \& Bartlett Learning; 2005

10. Barricarte A. Gripe aviar: ¿La pandemia que viene? Anales Sis San Navarra. 2006;29:7-11.

11. Torrijos JD, Tuells J. La «gripe española» según el diario España Médica (1918-1919). Vacunas. 2015;16:81-6.

12. Recordamos la pandemia de influenza de 1918 [Internet]. EE.UU.: Centro para el Control y la Prevención de Enfermedades [fecha última actualización: 23 de mayo de 2020]. Disponible en: https://www.cdc.gov/spanish/especialescdc/pandemia-influenza-1918/index.html

13. Pulido S. La gripe española: la pandemia de 1918 que no comenzó en España [Internet]. Gaceta Médica; 19 enero 2018 [fecha de consulta: 27 abril 2020]. Disponible en: https://gacetamedica.com/investigacion/la-gripeespanola-la-pandemia-de-1918-que-no-comenzo-en-espana-fy1357456/

14. Markel H, Lipman HB, Navarro JA, Sloan A, Michalsen JR, Stern AM, et al. Nonpharmaceutical interventions implemented by US cities during the 1918-1919 influenza pandemic. JAMA. 2007;298:644-54.

15. World Health Organization. Ethical considerations in developing a public health response to pandemic influenza (No. WHO/CDS/EPR/ GIP/2007.2). Ginebra: World Health Organization; 2007.

16. Delpiano L, Astroza L, Toro J. Sarampión: la enfermedad, epidemiología, historia y los programas de vacunación en Chile. Revista Chil Infectol. 2015;32:417-29.
17. Casos confirmados por sarampión 2020 [Internet]. México: Subsecretaría de prevención y promoción de salud, Dirección General de Epidemiología, Dirección de vigilancia epidemiológica de enfermedades transmisibles; 12 de junio de 2020. Disponible en: https://www.gob.mx/ salud/documentos/casos-confirmados-por-sarampion-2020

18. Visión general de la infección por el VIH/SIDA. Conceptos básicos [Internet]. Departamento de Salud y Servicios Humanos de EE.UU., Centro de Control de Enfermedades; 2019 [fecha de consulta: 29 abril 2020]. Disponible en: https://infosida.nih.gov/

19. Organización Mundial de la Salud. VIH/sida [Internet]. 2019. [consulta 29 abril 2020]. Disponible en: https://www.who.int/es/news-room/factsheets/detail/hiv-aids

20. Organización de las Naciones Unidas. El SIDA en cifras [Internet]. ONUSIDA; 2019 [fecha de consulta: 2 mayo 2020]. Disponible en: https://www. unaids.org/es

21. Crespo Domínguez F, Castellón Lozano R, Cárdenas Almagro AS, Licea González A. Enfoque bioético y social de la infección por el virus de inmunodeficiencia humana. Humanid Méd. 2014;14:387-406.

22. López M, García J, Pacheco R, Escamilla R, Villanueva M. La influenza A/ H1N1 2009. Una crónica de la primera pandemia del siglo XXI [Internet]. México, Ciudad de México: Dirección General de Servicios de Cómputo Académico-UNAM, Revista Digital Universitaria; 1 de abril de 2010 [fecha de consulta: 2 mayo 2020]. Disponible en: http://www.revista.unam.mx/ vol.11/num04/art37/int37.htm

23. Krammer F, Smith GJD, Fouchier RAM, Peiris M, Kedzierska K, Doherty PC, et al. Influenza. Nat Rev Dis Prim. 2018;4:1-21.

24. González L, Orraca O, Sanabria J. La influenza A (H1N1): estado actual del conocimiento Rev Ciencias Médicas Pinar del Río. 2010;14: 295-313.

25. Enfermedad por el virus del Ébola [Internet]. World Health Organization; 2020 [fecha de consulta: 4 mayo 2020]. Disponible en: https://www.who. int/es/news-room/fact-sheets/detail/ebola-virus-disease

26. Ethical considerations for use of unregistered interventions for Ebola virus disease (EVD) [Internet]. World Health Organization; 2020 [fecha de consulta: 2 mayo 2020]. Disponible en: https://www.who.int/es/ news-room/detail/12-08-2014-ethical-considerations-for-use-of-unregistered-interventions-for-ebola-virus-disease-(evd)

27. Ferrer Salvans P. Cómo afrontar el Ébola, perspectivas de tratamiento. Bioética y debate. 2014;73:9-14.

28. Camps V. Breve historia de la ética. Barcelona, España: RBA; 2017.

29. Hartmann N. Ética. Madrid, España: Ediciones Encuentro; 2011.

30. Loewy EH. Textbook of medical ethics. Países Bajos: Springer Netherlands; 2013.

31. La Comisión Nacional de Bioética. Pronunciamiento Institucional. La bioéstica ante la pandemia del COVID-19 [Internet]. México: Comisión Nacional de bioética [fecha de consulta: 8 mayo 2020]. Disponible en: https://www.gob.mx/salud/conbioetica

32. Kim SYH, Grady C. Ethics in the time of COVID: What remains the same and what is different. Neurology. 2020;94(23):1007-8.

33. Beca JP. Una mirada ética en las epidemias [Internet]. Facultad de Medicina, Clínica Alemana, Universidad del desarrollo; 2009. Disponible en: https://medicina.udd.cl/centro-bioetica/files/2010/08/Una-mirada$\%$ C3\%A9tica-a-las-epidemias.pdf

34. Información importante Coronavirus COVID-19 [Internet]. Gobierno de México [fecha de consulta: 8 mayo 2020]. Disponible en: https://www. gob.mx/salud

35. Ruiz Chávez MH. Pronunciamiento. La bioética ante la pandemia del COVID-19 [Internet]. Gobierno de México [fecha de consulta: 8 mayo 2020]. Disponible en: https://www.gob.mx/salud/conbioetica

36. Ethics in epidemics, emergencies and disasters: Research, surveillance and patient care. Training manual [Intenet]. World Health Organization; 2015 [fecha de consulta: 6 mayo 2020]. Disponible en: http://apps.who. int/iris/bitstream/10665/196326/1/9789241549349 eng.pdf

37. Kramer JB, Brown DE, Kopar PK. Ethics in the time of coronavirus: Recommendations in the COVID-19 pandemic. J Am Coll Surg. 2020;230(6):1114-8

38. AMA Code Of Medical Ethics [Internet]. EE.UU.: American Medical Association. Disponible en: https://www.ama-assn.org/delivering-care/ ethics/code-medical-ethics-overview

39. Consideraciones éticas en el desarrollo de una respuesta de salud pública a la gripe pandémica [Internet]. Ginebra: Organización Mundial de la Salud; 2009. Disponible en: https://www.who.int/ethics/WHO_CDS_ EPR_GIP_2007.2_spa.pdf

40. Orientación ética sobre cuestiones planteadas por la pandemia del nuevo coronavirus [Internet]. Organización Panamericana de la Salud, Organización Mundial de la Salud; 2020. Disponible en: https://www.paho. org/es/documentos/orientacion-etica-sobre-cuestiones-planteadaspor-pandemia-nuevo-coronavirus-covid-19 